\title{
COVID-19 and HIV infection co-pandemics and their impact: a review of the literature
}

Sivaporn Gatechompol ${ }^{1,2}$, Anchalee Avihingsanon ${ }^{1,2}$, Opass Putcharoen ${ }^{3}$, Kiat Ruxrungtham ${ }^{4^{*}}$ and Daniel R. Kuritzkes ${ }^{5}$

\begin{abstract}
Coronavirus disease 2019 (COVID-19) was first detected in December 2019. In March 2020, the World Health Organization declared COVID-19 a pandemic. People with underlying medical conditions may be at greater risk of infection and experience complications from COVID-19. COVID-19 has the potential to affect People living with HIV (PLWH) in various ways, including be increased risk of COVID-19 acquisition and interruptions of HIV treatment and care. The purpose of this review article is to evaluate the impact of COVID-19 among PLWH. The contents focus on 4 topics: (1) the pathophysiology and host immune response of people infected with both SARS-CoV-2 and HIV, (2) present the clinical manifestations and treatment outcomes of persons with co-infection, (3) assess the impact of antiretroviral HIV drugs among PLWH infected with COVID-19 and (4) evaluate the impact of the COVID-19 pandemic on HIV services.
\end{abstract}

Keywords: COVID-19, HIV, Co-infection, Pathophysiology, Clinical, Outcome

\section{Introduction}

In December 2019, a cluster of cases of pneumonia was reported in Wuhan, Hubei Province, China. The source of the infection was later identified as severe acute respiratory syndrome coronavirus 2 (SARS-CoV-2), which causes the coronavirus disease 2019 (COVID-19). On March 11, 2020 the World Health Organization (WHO) declared COVID-19 as a global pandemic [1]. As of 22 March 2021, more than 123 million cases have been confirmed globally along with 2.7 million deaths [2]. Older age and comorbidities such as hypertension, diabetes and cardiovascular disease are risk factors for developing severe COVID-19 and are associated with a high mortality rate [3-5]. However, data are limited on the impact of COVID-19 on people living with HIV (PLWH) who may be considered an immunocompromised population. Globally, there are 38 million PLWH, 690,000 of whom died of HIV-related illnesses in 2019 [6]. The WHO

\footnotetext{
*Correspondence: rkiat@chula.ac.th

${ }^{4}$ Chula Vaccine Research Center (ChulaVRC)Faculty of Medicine, Chulalongkorn University, Bangkok, Thailand

Full list of author information is available at the end of the article
}

estimated that only $67 \%$ of PLWH were on antiretroviral therapy (ART) worldwide in 2019 [7]; only $60 \%$ of the people with HIV infection were aware of their HIV status [8]. Therefore, PLWH not on ART or whose disease is not well controlled may be at increased risk for contracting COVID-19 because their immune systems are compromised. Such persons may also be at increased risk for developing serious symptoms and death if infected with COVID-19. Limited information is available, however, regarding the treatment and outcome of SARS-CoV-2 infection among PLWH.

Recently, many countries have reported disruptions in the delivery of HIV services and care due to the COVID-19 pandemic [9]. This disruption may increase the morbidity and mortality among PWLH beyond those infected with COVID-19 [10, 11]. However, the information regarding the impact of COVID-19 on HIV services is scarce.

In this review, we describe the pathophysiology and host immune response of people infected with both SARS-CoV-2 and HIV, present the clinical manifestations and treatment outcomes of persons with co-infection, 
assess the impact of antiretroviral HIV drugs among PLWH infected with COVID-19 and evaluate the impact of the COVID-19 pandemic on HIV services.

\section{Pathophysiology and host immune response to SARS-CoV-2 and HIV infections}

The pathophysiology and immune response of people infected with COVID-19 has been reviewed $[12,13]$. In brief, SARS-CoV-2 is a $\beta$ coronavirus characterized by its four structural proteins: Spike (S), membrane (M), envelop (E) and nucleocapsid (N) [14]. The life cycle of SARS-CoV-2 consists of the following 5 steps: attachment, penetration, biosynthesis, maturation and release [12]. Angiotensin converting enzyme 2 (ACE2) is the receptor for SARS-CoV-2 $[15,16]$. Single-cell RNA sequencing has shown that ACE2 is highly expressed in the lung, heart, ileum, kidney and bladder [17]. In addition, the acute loss of smell (anosmia) has been reported in patients with COVID-19 [18]. However, ACE2 was not detected in either olfactory sensory neurons or olfactory bulb neurons [19]. Therefore, infection of non-neuronal cell types may be primary source leads to olfactory dysfunction in patients with COVID-19.

After SARS-CoV-2 infects epithelial cells of the upper respiratory tract, virus produced by infected cells travels to the lower airway, infecting bronchial and alveolar epithelial cells and alveolar macrophages [20]. As a consequence of innate immunity, virus-infected epithelial cells undergo apoptosis and are phagocytized by antigen presenting cells (APC) such as dendritic cells (DCs) and macrophages. The APC migrate to draining lymph nodes to present viral antigens to T cells [12]. Both CD4+ and $\mathrm{CD} 8+\mathrm{T}$ cells play a major role in fighting against the coronavirus [21]. $\mathrm{CD} 4+\mathrm{T}$ cells activate $\mathrm{B}$ cells to promote the production of virus-specific antibodies, while CD8+ T cells can directly kill virally infected cells [12]. In severe COVID-19, interstitial mononuclear inflammatory infiltrates, dominated by lymphocytes, are seen in lung biopsy [22]. Furthermore, desquamation of pneumocytes and pulmonary oedema with hyaline membrane formation indicating acute respiratory distress syndrome (ARDS) have been reported [22, 23]. A summary of the pathophysiology and clinical manifestations of COVID19 are shown in Fig. 1.

In contrast, HIV binds to the CD4 receptor of the host cell, followed by engagement of a co-receptor (i.e., chemokine receptor 5 (CCR5) or chemokine receptor 4 (CXCR4)). The characteristics of SARS-CoV-2 are compared to HIV in Table 1. All CD4 positive cells (i.e., T helper cells), macrophages, dendritic cells and astrocytes are susceptible to HIV [24]. Direct viral cytopathic effects of HIV as well as indirect effects including host innate immune response to viral DNA produced during abortive infection and endotoxin/microbial translocation from leaky guts, persistent immune activation, immune dysregulation and $\mathrm{CD} 4 \mathrm{~T}$ cell homeostasis failure are keys to the pathogenesis of HIV that leads to CD4 T cell depletion and immune compromise in HIV [25-27]. A summary of the host immune response following exposure to HIV is shown in Fig. 2.

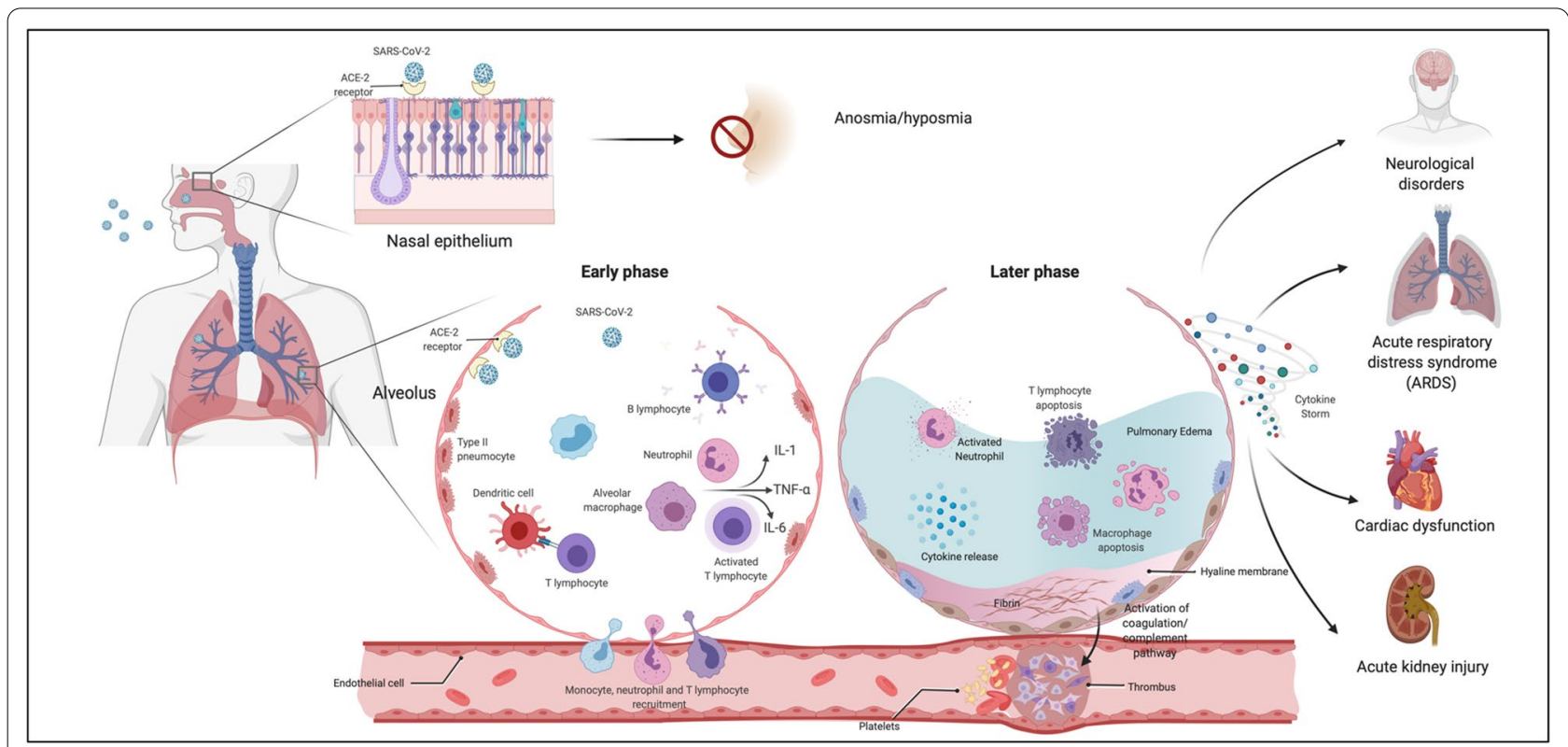

Fig. 1 Pathophysiology and clinical manifestations of COVID-19. Created with BioRender.com 
Table 1 The comparison between SARS-COV 2 and HIV characteristics

\begin{tabular}{|c|c|c|}
\hline & SAR-CoV 2 & HIV \\
\hline Classification of virus & $\beta$ coronaviruses & Lentiviruses \\
\hline Virus size in diameter & $60-140 \mathrm{~nm}$ & $100 \mathrm{~nm}$ \\
\hline Receptor binding domain & Angiotensin converting enzyme 2 (ACE2) receptor & CD4 T cell receptor and co-receptor CCR5, CXCR4 \\
\hline $\begin{array}{l}\text { High expression of the } \\
\text { receptor in human } \\
\text { organ }\end{array}$ & $\begin{array}{l}\text { lung, heart, } \\
\text { ileum, kidney and bladder }\end{array}$ & Various lymphoid tissues \\
\hline Primary affected cells & T cell lymphocytes & T cell lymphocytes \\
\hline Immune activation & Acute cytokine storm & $\begin{array}{l}\text { Chronic immune activation (with slow progressive } \\
\text { immunodeficiency) }\end{array}$ \\
\hline Transmission & Droplet, contact, airborne & Sexual transmission is the most common route, blood \\
\hline Prevention & Mask, Social distancing & $\begin{array}{l}\text { Condom use, Pre-exposure prophaylaxis (PrEP), and } \\
\text { treatment as prevention (TasP) }\end{array}$ \\
\hline Vaccine & $\begin{array}{l}\text { As of } 17 \text { March 2021, } 6 \text { vaccines are authorized for emergency use } \\
\text { based on preliminary evidence that they are safe and effective } \\
\text { and } 7 \text { vaccines are approved for full use in few countries }\end{array}$ & Unlikely up-to-now \\
\hline
\end{tabular}

* Available from https://www.nytimes.com/interactive/2020/science/coronavirus-vaccine-tracker.html

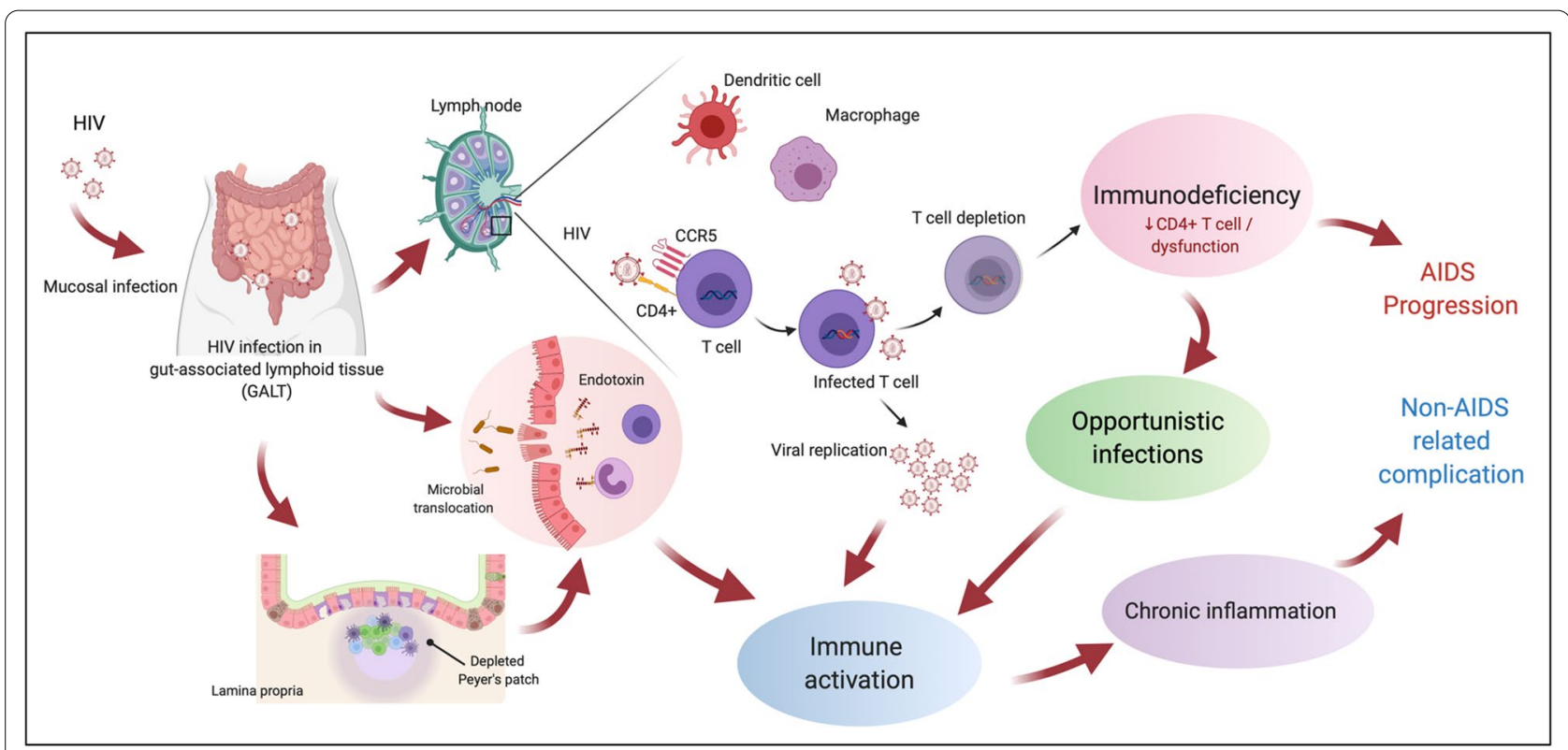

Fig. 2 Host immune response following exposure to HIV. Created with BioRender.com

The lymphocyte analysis studies among patients with COVID-19 demonstrate that $\mathrm{T}$ lymphopenia-in particular, a decrease in CD4+ $\mathrm{T}$ cells-were common among patients with COVID-19, and more evident in severe cases $[28,29]$. If superimposed on low CD4 counts in patients with advanced HIV disease, the lymphopenia of COVID-19 could delay the clearance of SARS$\mathrm{CoV}-2$ and promote disease progression. Moreover, COVID-19-associated pulmonary aspergillosis (CAPA) among severely ill COVID-19 patients has been reported worldwide, raising concerns of an additional contributing factor to mortality [30-32]. The pathological factors that may be associated with CAPA are the damaged respiratory epithelium, dysfunctional mucociliary clearance and low immune response, including low CD4 cell count [33, 34].

Elevated levels of multiple proinflammatory cytokines such as IL-2, IL-6, IL-10, and IFN- $\gamma$ in severe cases of COVID-19 cannot only promote a hypercoagulable state, but also enhance the pro-thrombotic functions [35]. 
Moreover, a study reported a pattern of tissue damage consistent with complement-mediated microvascular injury among individuals with severe COVID-19 [36]. High incidence of thrombotic complications has been reported among COVID-19 patients admitted in intensive care unit [37].

HIV infection also is recognized as a prothrombotic condition [38-40]. Hence, COVID-19 and HIV co-infected patients could have a high risk of developing thrombosis. However, further studies are needed to prove this possibility.

\section{Clinical presentation and treatment outcome of COVID-19 among patients with HIV infection}

Although several large cohort studies have reported the clinical characteristics and treatment outcome of COVID-19 in the general population [3, 4], clinical outcomes data on COVID-19 among patients with HIV are sparse. In this section, we summarize the demographics, clinical presentation and treatment outcome of COVID19 among HIV-infected individuals from case series as well as epidemiological and cohort studies (Table 2).

Many studies conducted among PLWH with COVID19 reported a median age range between 40 and 61 years and majority of them were men, which is similar to that reported in the general population [3, 4]. Most of the PLWH with COVID-19 were on antiretroviral therapy and were virologically suppressed. The incidence rate of COVID-19 infection among PLWH differs by country. The US (0.8\%) [3] and Spain (1.8\%) [41] reported an incidence based on PCR whereas China (0.68\%) [42] used both PCR and clinical diagnosis. However, the rate of COVID-19 and HIV co-infection may be overestimated because PLWH are considered a high-risk population for developing complications and thus may be tested more frequently for COVID-19 compared to other populations. It has been reported that among COVID-19 and HIV co-infected patients, there is a high prevalence of comorbidities such as hypertension, diabetes and chronic kidney disease. The most common symptoms of COVID19 detected were fever, cough or shortness of breath [4346] which are similar to those reported in people without HIV [3, 47].

According to a case series, COVID-19-related mortality is high among immunosuppressed persons such as kidney transplant recipients and cancer patients [48]. There is a concern that COVID-19 disease may be more severe in persons with immunodeficiency or immune dysregulation. However, most PLWH infected with COVID-19 were reported to be on ART and had well controlled HIV infection. These people had suppressed HIV viral load and CD4 cell count $>350$ cells $/ \mathrm{mm}^{3}$. Previous studies have reported that nadir and recent $\mathrm{CD} 4+\mathrm{T}$ cell counts or viral suppression preceding COVID-19 presentation were not associated with mortality $[43,49,50]$. No significant differences were reported in clinical characteristics, treatments, or outcomes between HIV individuals with recent CD4 counts $<200$ or $\geq 200$ cells per $\mu \mathrm{L}$ [41].

The demographic data, clinical presentation and treatment outcome among PLWH co-infected with COVID19 are summarized in Table 2. Most of the PLWH co-infected with COVID-19 have had mild to moderate disease [41, 43, 44, 49,51-56]. However, two studies reported that the majority of COVID-19 cases among PLWH were severe and associated with a high mortality rate $[45,46]$. Additionally, risk factors for severe COVID19 among PLWH were similar to those without HIV such as older age and comorbid medical conditions $[42,55]$.

\section{The impact of antiretroviral HIV drugs among patients co-infected with COVID-19}

The $\mathrm{S}$ protein of the coronavirus mediates viral entry into targeted cells by binding to its receptor, ACE2, which leads eventually to viral fusion with the host cell membrane. However, the $\mathrm{S}$ protein is synthesized as an inactive precursor that requires activation by host cell proteases TMPRSS2 or cathepsin B or L to become a fusion active form. Thus, protease inhibitors have been considered as a candidate therapy for SARS-CoV and other coronaviruses $[57,58]$. Treatment with the HIV protease inhibitor with lopinavir/ritonavir (LPV/r) showed some benefit in a non-human primate model of MERS-CoV infection [59]. Recent in vitro studies reported that antiviral activity of $\mathrm{LPV} / \mathrm{r}$ against SARS-CoV-2, albeit at a relatively high $\mathrm{EC}_{50}[60,61]$. However, several observational studies and case reports demonstrated that the clinical benefit of using LPV/r among COVID-19 patients was inconclusive [62-65]. Moreover, a randomized, controlled open-label trial conducted in hospitalized adult patients with severe COVID-19 failed to show a statistically significant difference in time to clinical improvement or mortality in the $\mathrm{LPV} / \mathrm{r}$-treated group as compared to standard of care [66]. Moreover, LPV/r treatment was stopped early in 13 patients (13.8\%) because of adverse events. The lack of clinical benefit of LPV/r for COVID-19 was confirmed in the RECOVERY and SOLIDARITY trials [67, 68].

In vitro data show the absence of any anti-SARS-CoV-2 activity of darunavir [69]. This finding is corroborated by the clinical observation that PLWH receiving a darunavir-containing regimen were not protected from COVID19 [70].

Antiviral activity of tenofovir against SARS-CoV-2 has been demonstrated in virtual and in vitro studies [71, 72]. These results led to speculation that tenofovir disoproxil fumarate (TDF) - and tenofovir alafenamide (TAF)-containing antiretroviral regimens might have a protective 


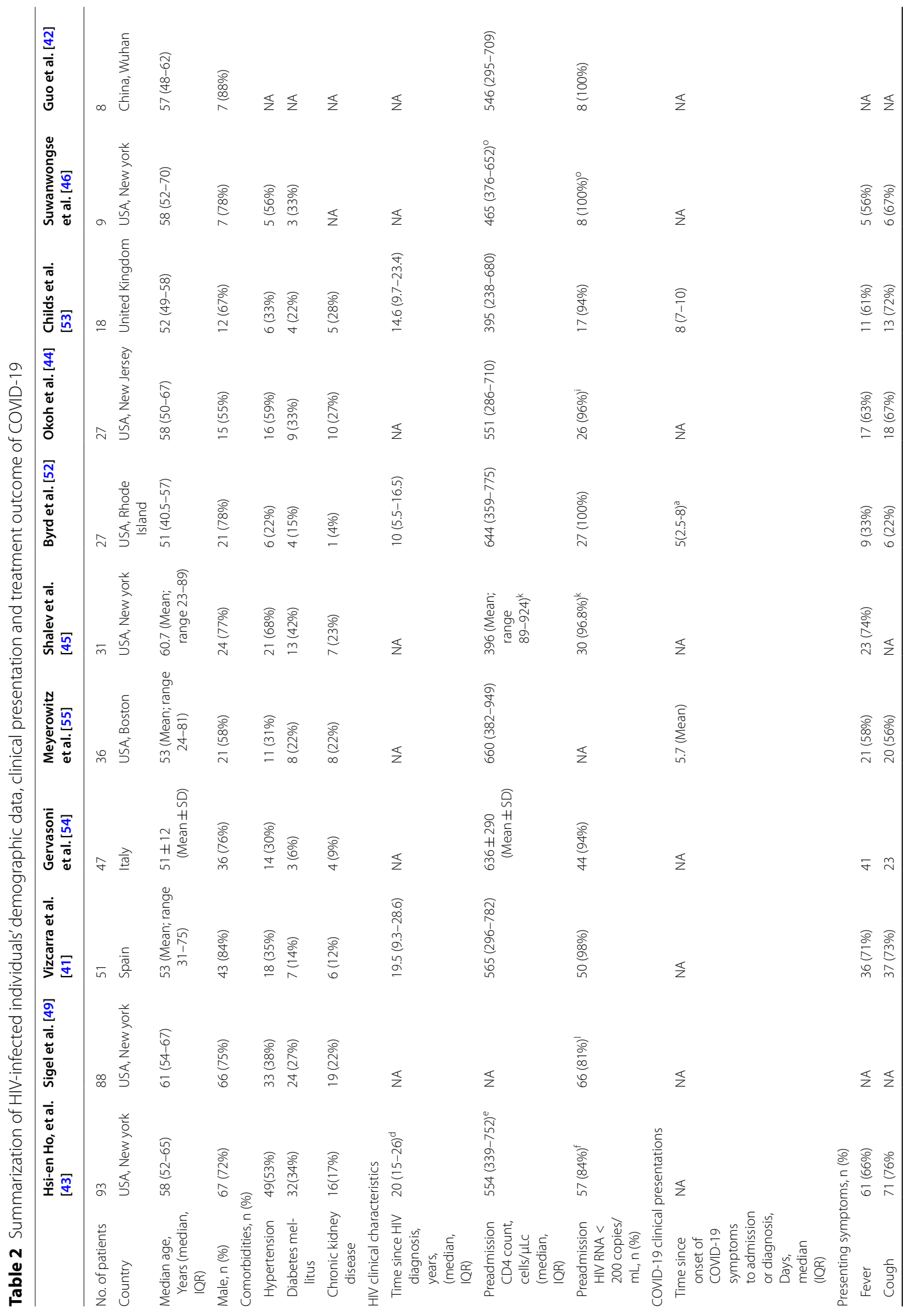




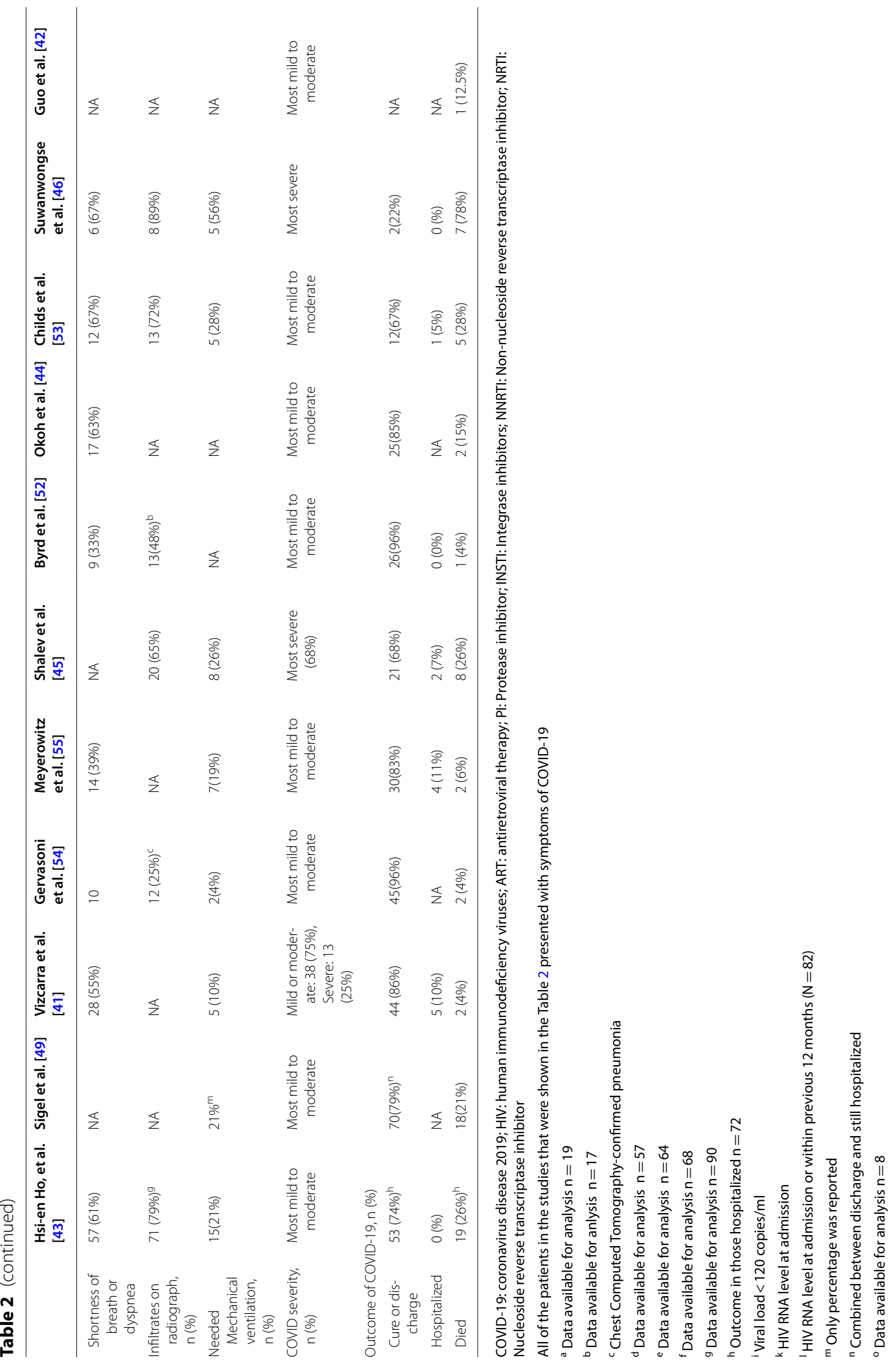


effect against COVID-19 [3]. However, a prospective cohort in Spain observed a higher rate of COVID-19 infection among PLWH on TAF or TDF [41]. This finding supports the results from case series that tenofovirbased ART does not provide any clinical benefit against COVID-19 among PLWH $[45,52]$. Therefore, up until now, the use of antiretroviral agents has no clinical benefit for the treatment or prevention of COVID-19.

\section{HIV service during COVID-19 outbreak}

COVID-19 pandemic has had an unprecedented negative impact on HIV services and care across the globe. According to a WHO report, between April and June 202073 countries faced the risk of ART disruption affecting 17.7 million people receiving ART [9]. A modelling study done by WHO and UNAIDS estimated that a 6-month disruption of ART could lead to more than 500,000 extra deaths from AIDS-related illnesses in subSaharan Africa in 2020-2021 [73].

Several factors have contributed to the disruptions in HIV service and care during the COVID-19 pandemic. First, the strict quarantine measures and transportation lock downs were implemented in many cities to control the spread of COVID-19. A survey from China reported that PLWH who returned to their home towns could not refill their medication due to the lock down [74]. Not surprisingly, the shortage of ART affected not only the physical health status of PLWH but also caused considerable psychological stress. Postal delivery of drugs is one approach to ensure that PLWH have a continuous supply of ARVs. However, this method poses implementation challenges because not all PLWH want ARVs delivered to their homes in order to maintain privacy and guard against unwanted disclosure of their HIV status to household members [75]. Second, there have been shortages of ARV because of shut downs by certain drug manufacturers [9]. Third, healthcare workers who provide care for PLWH were diverted to care for patients with COVID-19 [75-77]. A survey performed in Central and Eastern Europe reported that infectious disease physicians shifted their focus to take care COVID-19 patients instead of PLWH [78].

During this difficult time, healthcare systems must develop effective strategies for balancing healthcare resources need by both PLWH and patients with COVID-19. ARV multi month dispensing (MMD) policy has been adopted in many countries [9] in order to prevent disruptions of ARV supplies for PLWH and to reduce their exposure to COVID-19 when accessing HIV services. Telemedicine platforms have been proposed as a strategy for continued provision of healthcare to PLWH in response to COVID-19 during the lock-down period and have been implemented successfully in many settings
[79]. A multidisciplinary approach to help PLWH maintain their physical and mental health has never been more important than now, in the face of the COVID19 pandemic. In addition, other services for prevention and treatment of opportunistic infection and sexually transmitted infections may be disrupted during COVID19 pandemic. This lockdown related disruptions may increase in burden of TB and sexually transmitted infections [80-82].

\section{Conclusion}

Even though lymphopenia associated with COVID19 may further decrease CD4+ T cell counts in PLWH, there are no differences in the clinical presentations, outcomes, morbidity and mortality between individuals who have SARS-CoV-2 with or without HIV infection. Several randomized control trials have shown that antiretroviral therapy has no beneficial effect among people infected with SARS-CoV-2 compared to standard of care.

To date, we still do not have any proven antiviral agents that reduce mortality among COVID-19 patients. Right now, the medical resources have shifted towards COVID19 but it should be noted that we should not overlook the care for PLWH who still need ART and follow-up care. We should use several innovative service deliveries and MMD policy to help PLWH have continuous supply of ARV during this outbreak.

\section{Abbreviations}

HIV: Human immunodeficiency viruses; COVID-19: Coronavirus disease 2019; SARS-CoV-2: Severe acute respiratory syndrome coronavirus 2; WHO: World Health Organization; PLWH: People living with HIV; ART: Antiretroviral therapy; ACE2: Angiotensin converting enzyme 2; APC: Antigen presenting cells; DCs: Dendritic cells; ARDS: Acute respiratory distress syndrome; CCR5: Chemokine receptor 5; CXCR4: Chemokine receptor 4; LPV/r: Lopinavir/ritonavir; TDF: Tenofovir disoproxil fumarate; TAF: Tenofovir alafenamide; MMD: Multi month dispensing.

\section{Acknowledgements \\ We would like to thank the medical staff for taking care of the patients during the outbreak. We would like to thank Pirapon June Ohata for proofreading the} manuscript.

\section{Authors' contributions}

SG performed the literature review, produced the figure, wrote and revised the manuscript. AA, OP edited the manuscript. KR and DK supervised and edited the manuscript. All authors read and approved the final manuscript.

\section{Funding}

No funding was used for the write-up of this review article.

Availability of data and materials

Not applicable.

\section{Declarations}

Ethics approval and consent to participate

Not applicable. 


\section{Consent for publication \\ Not applicable.}

\section{Competing interests}

The authors declare that they have no competing interests.

\begin{abstract}
Author details
${ }^{1}$ HIV-NAT, Thai Red Cross AIDS Research Centre, Bangkok, Thailand. ${ }^{2}$ Tuberculosis Research Unit, Faculty of Medicine, Chulalongkorn University, Bangkok, Thailand. ${ }^{3}$ Division of Infectious Disease, Department of Medicine, Faculty of Medicine, Chulalongkorn University, Bangkok, Thailand. ${ }^{4}$ Chula Vaccine Research Center (ChulaVRC)Faculty of Medicine, Chulalongkorn University, Bangkok, Thailand. 'Division of Infectious Diseases, Brigham and Women's Hospital, Harvard Medical School, Boston, MA, USA.
\end{abstract}

Received: 17 December 2020 Accepted: 8 April 2021 Published online: 05 May 2021

\section{References}

1. WHO. Timeline of WHO's response to COVID-19; Last updated 30 July 2020. https://www.who.int/news-room/detail/29-06-2020-covidtimeline. Accessed 1 Nov 2020

2. The Johns Hopkins Coronavirus Resource Center. COVID-19 data. https:// coronavirus.jhu.edu. Accessed 6 Nov 2020.

3. Richardson S, Hirsch JS, Narasimhan M, Crawford JM, McGinn T, Davidson $\mathrm{KW}$, et al. Presenting characteristics, comorbidities, and outcomes among 5700 patients hospitalized with COVID-19 in the New York City Area. JAMA. 2020;323:2052-9.

4. Guan WJ, Ni ZY, Hu Y, Liang WH, Ou CQ, He JX, et al. Clinical characteristics of coronavirus disease 2019 in China. N Engl J Med. 2020;382:1708-20.

5. Lithander FE, Neumann S, Tenison E, Lloyd K, Welsh TJ, Rodrigues JCL, et al. COVID-19 in older people: a rapid clinical review. Age Ageing. 2020:49:501-15

6. WHO. HIV/AIDS data and statistic. https://www.who.int/hiv/data/en/. Accessed 1 Nov 2020

7. WHO. Estimated Antiretroviral therapy coverage https://apps.who.int/ gho/data/view.main.23300REGION?lang=en. Accessed 1 Nov 2020

8. UNAIDS. Global HIV \& AIDS statistics-2018 fact sheet. Geneva: UNAIDS 2018. http://www.unaids.org/en/resources/fact-sheet.

9. WHO. Disruption in HIV, Hepatitis and STI services due to COVID-19. https://www.who.int/docs/default-source/hiv-hq/presentation-disru ption-in-services-international-aids-conference-2020.pdf?sfvrsn=d4bf1 f87_7. Accessed 1 Nov 2020.

10. El-Sadr WM, Justman J. Africa in the Path of Covid-19. N Engl J Med. 2020;383:e11.

11. Drain PK, Garrett N. SARS-CoV-2 pandemic expanding in sub-Saharan Africa: considerations for COVID-19 in people living with HIV. EClinicalMedicine. 2020;22:

12. Yuki K, Fujiogi M, Koutsogiannaki S. COVID-19 pathophysiology: a review. Clin Immunol. 2020;215:

13. Prompetchara E, Ketloy C, Palaga T. Immune responses in COVID-19 and potential vaccines: lessons learned from SARS and MERS epidemic. Asian Pac J Allergy Immunol. 2020;38:1-9.

14. Bosch BJ, van der Zee R, de Haan CA, Rottier PJ. The coronavirus spike protein is a class I virus fusion protein: structural and functional characterization of the fusion core complex. J Virol. 2003;77:8801-11.

15. Chen Y, Guo Y, Pan Y, Zhao ZJ. Structure analysis of the receptor binding of 2019-nCoV. Biochem Biophys Res Commun. 2020;525:135-40.

16. Letko M, Marzi A, Munster V. Functional assessment of cell entry and receptor usage for SARS-CoV-2 and other lineage B betacoronaviruses. Nat Microbiol. 2020;5:562-9.

17. Zou X, Chen K, Zou J, Han P, Hao J, Han Z. Single-cell RNA-seq data analysis on the receptor ACE2 expression reveals the potential risk of different human organs vulnerable to 2019-nCoV infection. Front Med. 2020;14:185-92.

18. Tong JY, Wong A, Zhu D, Fastenberg JH, Tham T. The prevalence of olfactory and gustatory dysfunction in COVID-19 Patients: a systematic review and meta-analysis. Otolaryngol Head Neck Surg. 2020;163:3-11.
19. Brann DH, Tsukahara T, Weinreb C, Lipovsek M, Van den Berge K, Gong $B$, et al. Non-neuronal expression of SARS-CoV-2 entry genes in the olfactory system suggests mechanisms underlying COVID-19-associated anosmia. Sci Adv. 2020;6:eabc5801.

20. Yoshikawa T, Hill T, Li K, Peters CJ, Tseng CT. Severe acute respiratory syndrome (SARS) coronavirus-induced lung epithelial cytokines exacerbate SARS pathogenesis by modulating intrinsic functions of monocyte-derived macrophages and dendritic cells. J Virol. 2009;83:3039-48.

21. Channappanavar R, Zhao J, Perlman S. T cell-mediated immune response to respiratory coronaviruses. Immunol Res. 2014;59:118-28.

22. Xu Z, Shi L, Wang Y, Zhang J, Huang L, Zhang C, et al. Pathological findings of COVID-19 associated with acute respiratory distress syndrome. Lancet Respir Med. 2020;8:420-2.

23. Wiersinga WJ, Rhodes A, Cheng AC, Peacock SJ, Prescott HC. Pathophysiology, transmission, diagnosis, and treatment of coronavirus disease 2019 (COVID-19): a review. JAMA. 2020;324:782-93.

24. Feng Y, Broder CC, Kennedy PE, Berger EA. HIV-1 entry cofactor: functional cDNA cloning of a seven-transmembrane, G protein-coupled receptor. Science. 1996;272:872-7.

25. Okoye AA, Picker LJ. CD4(+) T-cell depletion in HIV infection: mechanisms of immunological failure. Immunol Rev. 2013;254:54-64.

26. Doitsh G, Greene WC. Dissecting how CD4 T cells are lost during HIV infection. Cell Host Microbe. 2016;19:280-91.

27. Alzahrani J, Hussain T, Simar D, Palchaudhuri R, Abdel-Mohsen M, Crowe SM, et al. Inflammatory and immunometabolic consequences of gut dysfunction in HIV: parallels with IBD and implications for reservoir persistence and non-AIDS comorbidities. EBioMedicine. 2019;46:522-31.

28. Qin C, Zhou L, Hu Z, Zhang S, Yang S, Tao Y, et al. Dysregulation of immune response in patients with coronavirus 2019 (COVID-19) in Wuhan, China. Clin Infect Dis. 2020;71:762-8.

29. Wang D, Hu B, Hu C, Zhu F, Liu X, Zhang J, et al. Clinical characteristics of 138 hospitalized patients with 2019 novel coronavirus-infected Pneumonia in Wuhan, China. JAMA. 2020;323:1061-9.

30. Koehler P, Cornely OA, Böttiger BW, Dusse F, Eichenauer DA, Fuchs $F$, et al. COVID-19 associated pulmonary aspergillosis. Mycoses. 2020;63:528-34.

31. Alanio A, Dellière S, Fodil S, Bretagne S, Mégarbane B. Prevalence of putative invasive pulmonary aspergillosis in critically ill patients with COVID-19. Lancet Respir Med. 2020;8:e48-9.

32. Lansbury L, Lim B, Baskaran V, Lim WS. Co-infections in people with COVID-19: a systematic review and meta-analysis. J Infect. 2020;81:266-75.

33. Herold S, Becker C, Ridge KM, Budinger GRS. Influenza virus-induced lung injury: pathogenesis and implications for treatment. Eur Respir J. 2015;45:1463.

34. Rutsaert L, Steinfort N, Van Hunsel T, Bomans P, Naesens R, Mertes H, et al. COVID-19-associated invasive pulmonary aspergillosis. Ann Intensive Care. 2020;10:71.

35. Du F, Liu B, Zhang S. COVID-19: the role of excessive cytokine release and potential ACE2 down-regulation in promoting hypercoagulable state associated with severe illness. J Thromb Thrombolysis. 2021;51:313-29.

36. Magro C, Mulvey JJ, Berlin D, Nuovo G, Salvatore S, Harp J, et al. Complement associated microvascular injury and thrombosis in the pathogenesis of severe COVID-19 infection: a report of five cases. Transl Res. 2020;220:1-13.

37. Klok FA, Kruip M, van der Meer NJM, Arbous MS, Gommers D, Kant KM, et al. Incidence of thrombotic complications in critically ill ICU patients with COVID-19. Thromb Res. 2020;191:145-7

38. Bibas M, Biava G, Antinori A. HIV-Associated Venous Thromboembolism. Mediterr J Hematol Infect Dis. 2011;3:

39. Malek J, Rogers R, Kufera J, Hirshon JM. Venous thromboembolic disease in the HIV-infected patient. Am J Emerg Med. 2011;29:278-82.

40. Crum-Cianflone NF, Weekes J, Bavaro M. Review: thromboses among HIVinfected patients during the highly active antiretroviral therapy era. AIDS Patient Care STDS. 2008:22:771-8.

41. Vizcarra P, Pérez-Elías MJ, Quereda C, Moreno A, Vivancos MJ, Dronda F, et al. Description of COVID-19 in HIV-infected individuals: a single-centre, prospective cohort. Lancet HIV. 2020;7:e554-64.

42. Guo W, Ming F, Dong Y, Zhang Q, Zhang X, Mo P, et al. A survey for COVID19 among HIV/AIDS patients in two districts of Wuhan. SSRN: China; 2020. 
43. Ho HE, Peluso MJ, Margus C, Matias Lopes JP, He C, Gaisa MM, et al. Clinical outcomes and immunologic characteristics of Covid-19 in people with HIV. J Infect Dis. 2020;223(3):403-8.

44. Okoh AK, Bishburg E, Grinberg S, Nagarakanti S. COVID-19 pneumonia in patients with HIV-a case series. J Acquir Immune Defic Syndr. 2020;85(1):e4-5.

45. Shalev N, Scherer M, LaSota ED, Antoniou P, Yin MT, Zucker J, et al. Clinical characteristics and outcomes in people living with HIV hospitalized for COVID-19. Clin Infect Dis. 2020;71(16):2294-7.

46. Suwanwongse K, Shabarek N. Clinical features and outcome of HIV/ SARS-CoV-2 coinfected patients in The Bronx, New York city. J Med Virol. 2020;92(11):2387-9.

47. Goyal P, Choi JJ, Pinheiro LC, Schenck EJ, Chen R, Jabri A, et al. Clinical characteristics of covid-19 in New York City. N Engl J Med. 2020;382:2372-4.

48. Akalin E, Azzi Y, Bartash R, Seethamraju H, Parides M, Hemmige V, et al. Covid-19 and kidney transplantation. N Engl J Med. 2020;382:2475-7.

49. Sigel K, Swartz T, Golden E, Paranjpe I, Somani S, Richter F, et al. Covid-19 and people with HIV infection: outcomes for hospitalized patients in New York City. Clin Infect Dis. 2020;71(11):2933-8.

50. Karmen-Tuohy S, Carlucci PM, Zervou FN, Zacharioudakis IM, Rebick G, Klein E, et al. Outcomes among HIV-positive patients hospitalized with COVID-19. J Acquir Immune Defic Syndr. 2020;85:6-10.

51. Blanco JL, Ambrosioni J, Garcia F, Martínez E, Soriano A, Mallolas J, et al. COVID-19 in patients with HIV: clinical case series. Lancet HIV. 2020;7:e314-6.

52. Byrd KM, Beckwith CG, Garland JM, Johnson JE, Aung S, Cu-Uvin S, et al. SARS-CoV-2 and HIV coinfection: clinical experience from Rhode Island, United States. J Int AIDS Soc. 2020;23:

53. Childs K, Post FA, Norcross C, Ottaway Z, Hamlyn E, Quinn K, et al. Hospitalized patients with COVID-19 and HIV: a case series. Clin Infect Dis. 2020;71(8):2021-2.

54. Gervasoni C, Meraviglia P, Riva A, Giacomelli A, Oreni L, Minisci D, et al. Clinical features and outcomes of HIV patients with coronavirus disease 2019. Clin Infect Dis. 2020;71(16):2276-8.

55. Meyerowitz EA, Kim AY, Ard KL, Basgoz N, Chu JT, Hurtado RM, et al. Disproportionate burden of COVID-19 among racial minorities and those in congregate settings among a large cohort of people with HIV. Aids. 2020;34(12):1781-7

56. Ridgway JP, Farley B, Benoit JL, Frohne C, Hazra A, Pettit N, et al. A case series of five people living with HIV hospitalized with COVID-19 in Chicago, Illinois. AIDS Patient Care STDS. 2020;34:331-5.

57. Zhou Y, Vedantham P, Lu K, Agudelo J, Carrion R Jr, Nunneley JW, et al. Protease inhibitors targeting coronavirus and filovirus entry. Antiviral Res. 2015;116:76-84.

58. Li G, De Clercq E. Therapeutic options for the 2019 novel coronavirus (2019-nCoV). Nat Rev Drug Discov. 2020;19:149-50.

59. Chan JF, Yao Y, Yeung ML, Deng W, Bao L, Jia L, et al. Treatment with Iopinavir/ritonavir or interferon- $\beta 1 \mathrm{~b}$ improves outcome of MERS-CoV infection in a nonhuman primate model of common marmoset. J Infect Dis. 2015;212:1904-13.

60. Choy KT, Wong AY, Kaewpreedee P, Sia SF, Chen D, Hui KPY, et al. Remdesivir, lopinavir, emetine, and homoharringtonine inhibit SARS-CoV-2 replication in vitro. Antiviral Res. 2020;178:

61. Martinez MA. Compounds with therapeutic potential against novel respiratory, coronavirus. Antimicrob Agents Chemother. 2019;64:e00399.

62. Young BE, Ong SWX, Kalimuddin S, Low JG, Tan SY, Loh J, et al. Epidemiologic features and clinical course of patients infected with SARS-CoV-2 in Singapore. JAMA. 2020;323:1488-94.

63. Han W, Quan B, Guo Y, Zhang J, Lu Y, Feng G, et al. The course of clinical diagnosis and treatment of a case infected with coronavirus disease 2019. J Med Virol. 2020;92:461-3.

64. Liu F, Xu A, Zhang Y, Xuan W, Yan T, Pan K, et al. Patients of COVID-19 may benefit from sustained Lopinavir-combined regimen and the increase of
Eosinophil may predict the outcome of COVID-19 progression. Int J Infect Dis. 2020;95:183-91.

65. Chen N, Zhou M, Dong X, Qu J, Gong F, Han Y, et al. Epidemiological and clinical characteristics of 99 cases of 2019 novel coronavirus pneumonia in Wuhan, China: a descriptive study. Lancet. 2020;395:507-13.

66. Cao B, Wang Y, Wen D, Liu W, Wang J, Fan G, et al. A trial of lopinavirritonavir in adults hospitalized with severe covid-19. N Engl J Med. 2020;382:1787-99.

67. Horby PW, Mafham M, Bell JL, Linsell L, Staplin N, Emberson J, et al. Lopinavir-ritonavir in patients admitted to hospital with COVID-19 (RECOVERY): a randomised, controlled, open-label, platform trial. Lancet. 2020;396(10259):1345-52.

68. Pan H, Peto R, Henao-Restrepo AM, Preziosi MP, Sathiyamoorthy V, Abdool Karim Q, et al. Repurposed Antiviral Drugs for Covid-19 - Interim WHO Solidarity Trial Results. N Engl J Med. 2021;384:497-511.

69. De Meyer S, Bojkova D, Cinatl J, Van Damme E, Buyck C, Van Loock M, et al. Lack of antiviral activity of darunavir against SARS-CoV-2. Int J Infect Dis. 2020;97:7-10.

70. Riva A, Conti F, Bernacchia D, Pezzati L, Sollima S, Merli S, et al. Darunavir does not prevent SARS-CoV-2 infection in HIV patients. Pharmacol Res. 2020;157:

71. Elfiky AA. Ribavirin, remdesivir, sofosbuvir, galidesivir, and tenofovir against SARS-CoV-2 RNA dependent RNA polymerase (RdRp): a molecular docking study. Life Sci. 2020;253:

72. Jockusch S, Tao C, Li X, Anderson TK, Chien M, Kumar S, et al. Triphosphates of the Two Components in DESCOVY and TRUVADA are Inhibitors of the SARS-CoV-2 Polymerase. bioRxiv. 2020; 2020.04.03.022939.

73. Jewell BL, Mudimu E, Stover J, Ten Brink D, Phillips AN, Smith JA, et al. Potential effects of disruption to HIV programmes in sub-Saharan Africa caused by COVID-19: results from multiple mathematical models. Lancet HIV. 2020;7:e629-40.

74. Guo W, Weng HL, Bai H, Liu J, Wei XN, Zhou K, et al. Quick community survey on the impact of COVID-19 outbreak for the healthcare of people living with HIV. Zhonghua Liu Xing Bing Xue Za Zhi. 2020;41:662-6.

75. Sun S, Hou J, Chen Y, Lu Y, Brown L, Operario D. Challenges to HIV care and psychological health during the COVID-19 pandemic among people living with HIV in China. AIDS Behav. 2020;24:1-2.

76. Pinto RM, Park S. COVID-19 pandemic disrupts HIV continuum of care and prevention: implications for research and practice concerning community-based organizations and frontline providers. AIDS Behav. 2020;24:2486-9.

77. Shiau S, Krause KD, Valera P, Swaminathan S, Halkitis PN. The burden of COVID-19 in people living with HIV: a syndemic perspective. AIDS Behav. 2020;24:2244-9.

78. Kowalska JD, Skrzat-Klapaczyńska A, Bursa D, Balayan T, Begovac J, Chkhartishvili N, et al. HIV care in times of the COVID-19 crisis - where are we now in Central and Eastern Europe? Int J Infect Dis. 2020;96:311-4.

79. Rockwell KL, Gilroy A. Incorporating telemedicine as part of COVID-19 outbreak response systems. AJMC. 2020;26:147-8.

80. Cilloni L, Fu H, Vesga JF, Dowdy D, Pretorius C, Ahmedov S, et al. The potential impact of the COVID-19 pandemic on the tuberculosis epidemic a modelling analysis. EClinicalMedicine. 2020;28:

81. Crane MA, Popovic A, Stolbach Al, Ghanem KG. Reporting of sexually transmitted infections during the COVID-19 pandemic. Sex Transm Infect. 2020;97(2):101-2.

82. Lemoine M, Kim JU, Ndow G, Bah S, Forrest K, Rwegasha J, et al. Effect of the COVID-19 pandemic on viral hepatitis services in sub-Saharan Africa. Lancet Gastroenterol Hepatol. 2020;5:966-7.

\section{Publisher's Note}

Springer Nature remains neutral with regard to jurisdictional claims in published maps and institutional affiliations. 